\title{
CORRESPONDENCE
}

\section{Reply to 'Efficacy and safety of phosphodiesterase-5 inhibitors for treatment of erectile dysfunction secondary to spinal cord injury: a systemic review and meta-analysis'}

Spinal Cord Series and Cases (2017) 3, 16033; doi:10.1038/ scsandc.2016.33; published online 18 May 2017

The authors ${ }^{1}$ present a meta-analysis concerning the efficacy and safety of phosphodiesterase-5 inhibitors for the treatment of erectile dysfunction secondary to spinal cord injury. From a methodological standpoint, the authors are congratulated for their brilliant work. The search strategy, the data extraction and the statistical analysis were performed exactly according to the current guidelines for this type of publication. As a reader, having to counsel my patients with spinal cord injury, however, this review is not of essential value to me. Questions my patients ask me are: what is the chance that I will get an erection if I take the drug? If my answer is: the odds ratio is 11.997, with a $95 \%$ confidence interval 8.073-17.830, those of my patients who happened not to be statisticians (the majority, to be frank) will not be able to deal with the answer. They will like a percentage, for example, $2 / 3$ of the patients taking the drug have a satisfying erection. Next, they will ask me for the appropriate dosing and if it matters if they take the one or the other drug; the review does not mention any of these questions.

Please do not get me wrong: the authors did a good job and presented a solid meta-analysis. I congratulate them for their tedious and time-consuming work. The question to me is rather: are meta-analysis in the way we perform them now suitable to counsel our patients appropriately? Is evidence-based medicine, entirely based on thorough analysis of the existing data, the best method to deliver best patient care?

The editor states in the same edition of Spinal Cord $^{2}$ that the list of publications available online but waiting to be printed is getting increasingly longer. Maybe focusing on clinical research instead of creating a plethora of meta-analysis may be a way that helps all: the patients will be counseled due to new insights in innovative diagnostic/treatment methods, young researchers will spend their time on own research instead on analysis of previously published findings, and, as the former is extremely time-consuming, even the publication list may decrease.

\section{COMPETING INTERESTS}

The author declares no conflict of interest.

Jurgen Pannek

Neuro-Urologie, Schweizer Paraplegiker-Zentrum, Nottwil, Switzerland

Correspondence: J Pannek (juergen.pannek@paraplegie.ch)

\section{REFERENCES}

1 Jia D-D, Shuang W-B, Cheng T, Jia X-M, Zhang M. Efficacy and safety of phosphodieterase- 5 inhibitors for treatment of erectile dysfunction secondary to spinal cord injury: a systemic review and meta-analysis. Spinal Cord 2016; 54: 494-501.

2 Wyndaele JJ. Efficacy and safety of phosphodieterase-5 inhibitors for the treatment of erectile dysfunction secondary to spinal cord injury. Spinal Cord 2016; 54: 493. 